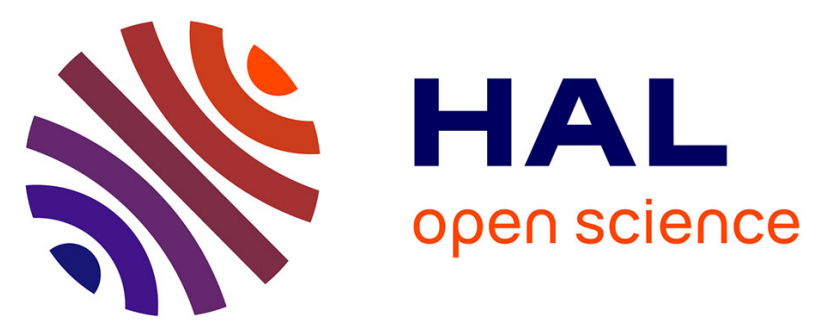

\title{
Evaluation of the Impact of Renal Failure on Correlation and Concordance Between 2 Free Light Chain Assays
}

Caroline Moreau, Brice Autier, Thibault Cavey, Emmanuel Rouger, James

Norwood, Claude Bendavid, Martine Escoffre, Martine Sébillot, Olivier

Decaux

\section{To cite this version:}

Caroline Moreau, Brice Autier, Thibault Cavey, Emmanuel Rouger, James Norwood, et al.. Evaluation of the Impact of Renal Failure on Correlation and Concordance Between 2 Free Light Chain Assays. Clinical lymphoma, 2016, 16 (12), pp.693-704. 10.1016/j.clml.2016.08.012 . hal-01427008

\section{HAL Id: hal-01427008 \\ https://hal-univ-rennes1.archives-ouvertes.fr/hal-01427008}

Submitted on 28 Mar 2018

HAL is a multi-disciplinary open access archive for the deposit and dissemination of scientific research documents, whether they are published or not. The documents may come from teaching and research institutions in France or abroad, or from public or private research centers.
L'archive ouverte pluridisciplinaire HAL, est destinée au dépôt et à la diffusion de documents scientifiques de niveau recherche, publiés ou non, émanant des établissements d'enseignement et de recherche français ou étrangers, des laboratoires publics ou privés. 


\section{Evaluation of the impact of renal failure on correlation and concordance between two free light chain assays}

Caroline Moreau ${ }^{1,2}$, Brice Autier ${ }^{1}$, Thibault Cavey ${ }^{1,2}$, Emmanuel Rouger ${ }^{1}$, James Norwood $^{3}$, Claude Bendavid $^{1,2}$, Martine Escoffre $^{3}$, Martine Sébillot $^{4}$, Olivier Decaux ${ }^{4}$.

${ }^{1}$ Laboratory of Biochemistry and Toxicology, University Hospital Center - Rennes France

2 INSERM U-991, University of Rennes 1, Rennes, France

${ }^{3}$ Department of clinical Hematology, University Hospital Center - Rennes France

${ }^{4}$ Department of Internal Medicine, University Hospital Center - Rennes France

Corresponding author: Dr Caroline MOREAU

Laboratoire de Biochimie CHU Pontchaillou - Unité INSERM 991

2, rue Henri Le Guilloux

35033 Rennes cedex France

caroline.moreau@chu-rennes.fr

Key words: free light chain, multiple myeloma, chronic kidney disease

List of abbreviations: CKD: chronic kidney disease; CKD-EPI: Chronic Kidney Disease Epidemiology Collaboration; FLC: free light chain; GFR: glomerular filtration rate; Ig: immunoglobulin; MGUS: monoclonal gammopathy of undetermined significance; SMM: smoldering multiple myeloma, indolent myeloma 


\section{Conflicts of interest}

The authors declare no conflicts of interest.

However, Siemens Healthcare Diagnosis provides reagents for the present study.

\section{MicroAbstract}

Measurement of serum free light chains (FLC) is recommended for diagnosis of monoclonal gammopathies. FLC measurements with Freelite ${ }^{\mathrm{TM}}$ (Binding Site) and N-Latex FLC (Siemens) assays were performed on 1215 fresh sera from patients with or without monoclonal gammopathy and renal failure. A good correlation was demonstrated between both assays, but it remained $7.6 \%-20.8 \%$ discordances between the methods related to the FLC-ratio interpretation. In patient's follow-up, few discrepancies were observed. Neither of the assays performed better than the other: they provide comparable but not equivalent results, and discrepancies are not linked to renal failure stage. Interpretation must take into account clinical data and the same assay must be used for patient's followup. 


\section{Abstract}

Background: Free light chains (FLC) assays are essential for diagnosis and follow-up of plasma cell dyscrasia. Two assays are available: Freelite ${ }^{\mathrm{TM}}$ (Binding Site) and N-Latex FLC (Siemens). The aim of our study was to evaluate the impact of renal failure on concordance and correlation between the two FLC assays.

Methods: FLC measurements using both assays were performed on 1215 fresh serum samples from patients with or without monoclonal gammopathy and renal failure. Concordance and correlation were evaluated using Passing-Bablock regression, Pearson correlation coefficient and Cohen's kappa coefficient taking into account the renal failure stage (evaluated with CKD-EPI formulae) and evaluation of treatment response in patients' follow-up.

Results: A good correlation was demonstrated between both assays, irrespective of the renal failure stage (Pearson correlation coefficient $>0.90$ ). For FLC ratio interpretation, there remained $7.6 \%$ to $20.8 \%$ discordances between the two methods throughout the whole range of renal impairment. To evaluate FLC evolution in patient's follow-up, 41 patients were selected with at least 6 consecutive serum samples being collected during the study period: we observed a concordant evolution of FLC concentrations between both assays. However, few discrepancies were observed with 4 patients.

Conclusions: Despite adjusted reference ranges for Freelite ${ }^{T M}$ FLC ratio, there remains about $\approx 12.5 \%$ discrepancies in interpretation of FLC ratio between the two available assays. They are not linked to renal failure stage and neither of the assays performed better than the other: results must be interpreted taking into account clinical data and the same assay must be used for patient's follow-up. 


\section{Introduction}

Monoclonal gammopathy constitutes a heterogenous family of pathologies including monoclonal gammopathy of undetermined significance (MGUS), multiple myeloma, smoldering multiple myeloma (SMM), and Waldenström macroglobulinemia. MGUS and SMM are asymptomatic, premalignant stages of multiple myeloma. However, SMM is at an intermediary clinical stage between MGUS and multiple myeloma, with a higher risk of progression to malignant disease ${ }^{1,2}$. To diagnose and monitor patients with monoclonal gammopathy, protein electrophoresis, immunofixation and kappa $(\kappa)$ and lambda $(\lambda)$ free light chains (FLC) measurement in serum are the gold standard. The FLC ratio (ratio of the concentration of K-FLC to $\lambda-F L C$, reflects FLC type's distribution. Since 2006, normalization of this ratio has been considered to be a marker for treatment response in recommendations ${ }^{3}$. Since 2011, the FLC ratio has become the definition of complete response for light chain multiple myelomas (LCMM) and non-secreting myelomas. Furthermore, the FLC ratio can be applied for prognostication ${ }^{4}$. At diagnosis, it represents an independent risk factor for progression in MGUS, SMM and multiple myeloma, as well as in solitary plasmacytoma ${ }^{5,6}$. Multiple myeloma diagnosis criteria were updated in 2014 by a consensus of the International Myeloma Working Group (IMWG) in order to integrate biological markers of malignity ${ }^{7}$. In Particular, these new criteria include a serum FLC ratio of involved / uninvolved FLC of 100 or greater, provided the absolute range of the involved FLC is at least $100 \mathrm{mg} / \mathrm{L}$. In this context, developing a method for FLC quantification is of special interest because it represents the tumor marker of choice directly connected to physiopathology. The first available method for FLC measurement was developed in 2001 by The Binding Site Company (Birmingham, UK) ${ }^{8}$. Freelite ${ }^{\mathrm{TM}}$ assay is an immunonephelometric or immunoturbidimetric method using polyclonal antibodies directed against the hidden epitopes of the FLC and it recognizes only FLC that are untied to heavy 
chain. In 2011, another N Latex FLC method using monoclonal antibodies was developed by Siemens (Marburg, Germany) ${ }^{9}$. These two assays are not entirely equivalent and seem to have limited clinical utility in detecting monoclonal gammopathy in some clinical situations, and care should be taken for interpretation if assays are switched ${ }^{10-17}$.

Plasma cells normally produce light chains in excess that do not bind to heavy chains to form complete immunoglobulin molecules and instead enter the bloodstream as FLC. The excess of polyclonal FLC is rapidly eliminated via glomerular filtration, followed by tubular reabsorption and degradation. In patients with chronic kidney disease (CKD) having a reduced glomerular filtration rate (GFR), the renal clearance of polyclonal FLC decreases and serum concentrations rise. In 2008, Hutchison et al. described an increase in the FLC $\mathrm{K} / \mathrm{\lambda}$ ratio using the Freelite ${ }^{\mathrm{TM}}$ method in CKD patients (estimated GFR $<60 \mathrm{~mL} / \mathrm{min} / 1.73$ $\mathrm{m}^{2}$ ) and established an extended FLC ratio reference range for these patients ${ }^{18}$. Similar work on the N Latex FLC method was performed by Jacobs et al. in 2014, who reported that reference values in the FLC $\mathrm{k} / \lambda$ ratio did not differ in CKD patients compared to healthy subjects ${ }^{19}$. They concluded that $\mathrm{N}$ Latex FLC ratio in CKD patients without monoclonal gammopathy was eGFR independent, with parallel increase of $\mathrm{k}$ and $\lambda$ FLC with decreasing eGFR. They also demonstrated that N Latex K-FLC and Freelite ${ }^{\mathrm{TM}} \mathrm{\kappa}-\mathrm{FLC}$ are similar in chronic kidney disease patients, whereas $N$ Latex $\lambda$-FLC are higher than Freelite $^{\mathrm{TM}} \lambda$-FLC in chronic kidney disease patients ${ }^{19}$. As twenty to forty percent of patients with newly diagnosed MM present renal impairment, and as renal impairment is a common complication of multiple myeloma ${ }^{20}$, it is important to understand the impact of renal function on the existing diagnostic methods. Do these two assays allow patients with monoclonal free light chain to be similarly identified? To address this issue, the aim of our study was to evaluate the concordance and the correlation between the two FLC assays in 1215 serum samples from patients with or without gammopathy. 


\section{Materials and methods}

\section{Samples}

This was a monocentric prospective study performed in Biochemistry laboratory of Rennes University Hospital. Consecutive sera of patients screened or followed-up for monoclonal gammopathy were collected between July 2012 and December 2012.

\section{FLC quantification}

FLC measurements were performed on fresh serum, within 5 days after blood sample, on a BN Prospec $®$ (immunonephelemeter, Siemens) using the Freelite ${ }^{\mathrm{TM}}$ commercial kit (The Binding Site Ltd, Birmingham, UK) based on polyclonal antibodies from sheep recognizing only FLC that are not bound to heavy chains ${ }^{8}$, and the $\mathrm{N}$ Latex FLC commercial kit (Siemens, Marburg, Germany) using a cocktail of monoclonal antibodies of murine origin ${ }^{9}$. Both kits were used according to manufacturer's instructions.

\section{FLC interpretation}

We chose to use the reference ranges proposed in the literature ${ }^{8,9,18}$ : Freelite ${ }^{\mathrm{TM}} \mathrm{K}-\mathrm{FLC}$ 3.30-19.40 mg/L, Freelite ${ }^{\mathrm{TM}} \lambda$-FLC 5.71-26.30 mg/L, Freelite ${ }^{\mathrm{TM}} \mathrm{FLC} \mathrm{k} / \lambda$ ratio 0.26-1.65 or 0.37-3.10 if renal insufficiency (eGFR $<60 \mathrm{~mL} / \mathrm{min} / 1.73 \mathrm{~m}^{2}$ ); N Latex K-FLC 6.7-22.4 mg/L, $\mathrm{N}$ Latex $\lambda$-FLC 8.3-27.0 $\mathrm{mg} / \mathrm{L}$ and $\mathrm{N}$ Latex FLC $\mathrm{K} / \lambda$ ratio0.31-1.56 without specific range required for CKD patients.

Renal function was assessed on basis of serum creatinine levels and GFR was estimated (eGFR) using CKD-EPI formula ${ }^{21}$. The GFR was defined as normal or slightly decreased when eGFR is either above or equal to $60 \mathrm{ml} / \mathrm{min} / 1.73 \mathrm{~m}^{2}$ (designated $C K D_{\geq 60}$ ). We 
consider a moderate renal insufficiency as the eGFR was $31-60 \mathrm{ml} / \mathrm{min} / 1.73 \mathrm{~m}^{2}$ (designated $\mathrm{CKD}_{31-60}$ ), severe renal insufficiency as eGFR $15-30 \mathrm{ml} / \mathrm{min} / 1.73 \mathrm{~m}^{2}$ (designated $\mathrm{CKD}_{15-30}$ ) and renal failure as eGFR less than $15 \mathrm{ml} / \mathrm{min} / 1.73 \mathrm{~m}^{2}$ (designated $\left.\mathrm{CKD}_{<15}\right)$

The purpose of FLC serum assay is to detect monoclonal components in the distribution of free light chains. The presence of a monoclonal component leads to an increase in the FLC $\mathrm{K} / \lambda$ ratio with a monoclonal $\mathrm{K}-\mathrm{FLC}$ and to a decrease FLC ratio with a monoclonal $\lambda$ FLC. We considered concordant results to be those with the same clinical interpretation of FLC ratio (normal or suspected monoclonality) and discordant to be those with a divergent clinical interpretation of FLC ratio with each assay. In patients with renal impairment, the Freelite $^{T M}$ FLC ratio reference ranges were adjusted to avoid monoclonality misinterpretations ${ }^{18}$.

To evaluate the correlation of FLC evolution during follow-up with both assays, patients with at least 6 consecutive samples were selected. We focused on patient's response to therapy. FLC response was examined even if the patients had measurable disease in serum and/or urines protein electrophoresis. Partial response (PR) and very good partial response (VGPR) were defined as $\geq 50 \%$ and $\geq 90 \%$ decrease, respectively, in the difference between involved and uninvolved FLC levels ${ }^{3}$.

\section{Statistical analysis}

To evaluate the correlation between the two assays, analysis of the quantitative results of $\mathrm{K}-\mathrm{FLC}, \lambda$-FLC and FLC $\mathrm{K} / \lambda$ ratio was performed using Passing-Bablock regression and Pearson correlation coefficient $r$.

To evaluate the qualitative concordance of the two tests, Cohen's kappa ( $\mathrm{k}$ ) coefficient was calculated. We concluded a complete agreement was when $\mathrm{k}=1$, a high agreement when 
$0.81 \leq k<1$ and a good agreement when $0.61 \leq K<0.80$. Statistical analyses were performed using SAS-Software Version 9.1 (SAS Institute, Cary, North Carolina, USA).

Due to of the low number of patients having serial samples, we did not perform statistical analysis for correlation during follow-up.

\section{Results}

\section{Quantitative analysis: FLC absolute value comparison}

In this cohort study, 1215 sera were measured for FLC with Freelite ${ }^{\mathrm{TM}}$ and N-Latex assays. Among these 1215 sera, 818 samples corresponding to 455 patients were assayed for FLC measurement with evaluated renal function: 144 samples were obtained from patients with normal renal function, 428 samples with moderate renal insufficiency, 154 samples with severe renal insufficiency and 92 samples with renal failure.

In the whole cohort, 368 patients suffered from monoclonal gammopathy, which represented 876 samples.

Figure 1 illustrates Passing-Bablock regressions for $\mathrm{k}-\mathrm{FLC}, \lambda-\mathrm{FLC}$ and $\mathrm{k} / \lambda$-FLC ratio for the 1215 sera and according to renal impairment.

As expected, MG- samples are essentially located within normal values.

With regard to the complete cohort of 1215 samples, a good correlation was observed between both assays with a Pearson correlation coefficient $>0.93$ (Figure 1A). Passing Bablock regressions for $\mathrm{k}-\mathrm{FLC}, \lambda-\mathrm{FLC}$ and $\mathrm{k} / \lambda$-FLC resulted in the conclusion that the bias between the two assays is neither constant nor proportional. In the low range for $\mathrm{k}$ and $\lambda$ FLC, higher results were observed with $\mathrm{N}$ Latex assay compared to Freelite ${ }^{\mathrm{TM}}$ assay. For the $\mathrm{K}-\mathrm{FLC}$ and $\lambda$-FLC below $7 \mathrm{mg} / \mathrm{L}$ (0.85 logged), an almost systematic negative bias was 
observed, which surpassed the limits of agreement below $4.5 \mathrm{mg} / \mathrm{L}$ (0.65 logged). A bias was noted in higher values for $\mathrm{K}$-FLC (from $155 \mathrm{mg} / \mathrm{L}$ ), $\lambda$-FLC (from $49.4 \mathrm{mg} / \mathrm{L}$ ) and the FLC $\mathrm{K} / \lambda$ ratio (from 11.6). We observed that concentrations obtained with the Freelite ${ }^{\mathrm{TM}}$ method were more elevated than those with N Latex FLC assay. Nevertheless, contrary to low values of FLC, the plots were not distributed exclusively, but only preferentially, on one side of the $y=x$-axis.

Results of the two assays according to renal failure stages were then compared $\left(C K D_{>60}\right.$, Figure 1B; $C K D_{31-60}$, Figure $1 \mathrm{C} ; \mathrm{CKD}_{15-30}$, Figure $1 \mathrm{D}$ and $\mathrm{CKD}_{<15}$, Figure $\left.1 \mathrm{E}\right)$. A good correlation between the two assays was demonstrated, irrespective of the renal failure stage (Pearson correlation coefficient $>0.90$, except for comparison of $\lambda$-FLC for CKD>60 $\mathrm{ml} / \mathrm{min} / 1.73 \mathrm{~m}^{2}$, Pearson correlation coefficient 0.874 ). As previously described in the whole cohort, the $\mathrm{N}$ Latex assay provides higher results in the low range and lower results in the high range, when compared with Freelite ${ }^{T M}$ method.

This observation concerning low values of $\mathrm{K}-\mathrm{FLC}$ and $\lambda$-FLC could be explained by the inability of Freelite ${ }^{T M}$ assay to reliably detect very low concentrations of FLC. Indeed, reproducibility studies performed in our laboratory for $\mathrm{k}-\mathrm{FLC}$ and $\lambda$-FLC in sera highlighted that the variation coefficient could rise up to $11.2 \%$ for low values of $\lambda$-FLC (data not shown). Of note, Pretorius et al. evaluated a variation coefficient up to $20 \%$ for this test in low values of $\lambda$-FLC ${ }^{22}$. We could therefore conclude that the two assays are good correlate in absolute values, irrespective of the renal failure stage.

When examined the results obtained in patients with or without gammopathy, it seems that patients with monoclonal gammopathy are not distributed differently across the different panels of renal failure stages. Moreover, we found a good correlation between both assays for $\mathrm{k}-\mathrm{FLC}$ in MG+ and MG- when eGFR>60 $\mathrm{ml} / \mathrm{min} / 1.73 \mathrm{~m}^{2}$. However, in this stage, 
Pearson correlation coefficient was always lower than 0.90 for $\lambda$-FLC (Figure 1B).

As concerns MG+ samples, we observed a good correlation $(R>0.90)$ between both assays for K-FLC and FLC ratio, irrespective of the renal failure stage. For $\lambda$-FLC, the correlation between the two assays is less good with $\mathrm{R}<0.90$ when eGFR was $<15$ $\mathrm{ml} / \mathrm{min} / 1.73 \mathrm{~m}^{2}$. Irrespective of the renal failure stage, concerning FLC ratio, Pearson correlation coefficient was greater than 0.93 in MG+.

With regard MG- samples, we observed a poor correlation between assays for FLC ratio when eGFR was less than $60 \mathrm{ml} / \mathrm{min} / 1.73 \mathrm{~m}^{2}$ (excepted for eGFR<15 $\mathrm{ml} / \mathrm{min} / 1.73 \mathrm{~m}^{2}$, probably due to the low effective n=14 MG-).

It seems that in patients with renal failure, the correlation between the two assays is better in patients with monoclonal gammopthy than in patients without monoclonal gammopathy.

\section{Qualitative analysis: clinical interpretation of FLC ratio}

The next step of our study was to evaluate the concordance of the clinical interpretation of FLC ratio.

For patients without renal impairment (eGFR>60 ml/min/1.73 $\left.\mathrm{m}^{2}\right), 79.2 \%(114 / 144)$ results were concordant (Table 1A). For patients with renal failure (eGFR $<60 \mathrm{ml} / \mathrm{min} / 1.73 \mathrm{~m}^{2}$ ), the rate of concordant results rose up to $92 \%$ (88.8 \% for $\mathrm{CKD}_{31-60}, 89.0 \%$ for $\mathrm{CKD}_{15-30}, 92.4 \%$ for $\mathrm{CKD}_{<15}$ ) (Table 1B-D). For patient with eGFR $<30 \mathrm{ml} / \mathrm{min} / 1.73 \mathrm{~m}^{2}$, we found a high agreement ( $\mathrm{k}$ coefficient $>0.81$ ) and for patient with $\mathrm{eGFR}>31 \mathrm{ml} / \mathrm{min} / 1.73 \mathrm{~m}^{2}$, we fond a good agreement $(0.61 \leq k$ coefficient $<0.80)$. These results confirmed that CKD was not linked to a higher rate of discordances when applying a specific reference range for Freelite $^{\mathrm{TM}}$ FLC ratio. Moreover, there remained $7.6 \%$ to $20.8 \%$ of discordances between the two methods throughout the whole range of renal impairment. In the whole cohort, 
$12.5 \%$ (102/818) of discordant results were observed, corresponding to 40 patients. Regarding the clinical data, these discrepancies are not exclusively in favor of either of the two assays and results should be interpreted on a case by case basis. In a few samples, these observations suggested that follow-up should be done with both assays to enable the clinician to interpret FLC results according to patient's clinical state. These discrepancies are currently under further evaluation.

These statistical tests were repeated including only the first sample of each patient to determine whether successive samples from the same patients have any influence on the study's consistency. Considering only the first sample of each patient $(N=457)$, it did not change our findings (data not shown).

We also studied the clinical interpretation in FLC ratio in patients with or without monoclonal gammopathy and with $\left(\mathrm{CKD}<60 \mathrm{ml} / \mathrm{min} / 1.73 \mathrm{~m}^{2}\right)$ or without $\left(\right.$ CKD>60ml/min $/ 1.73 \mathrm{~m}^{2}$ ) chronic kidney disease (Table 2). Our results showed a high agreement between the two assays in patients without monoclonal gammopathy and with renal failure (Table 2D) with a k-coefficient $>0.96$. These results could be explained because normal values of FLC ratio for Freelite ${ }^{\mathrm{TM}}$ were established in patients with chronic kidney disease without monoclonal gammopathy ${ }^{18}$. In contrast, for patients without chronic kidney disease and without monoclonal gammopathy, our results provided a good to low agreement with $\mathrm{k}$ coefficient $=0.61$ (Table $2 \mathrm{~A})$. It would be probably necessary to divide this group in 2 subgroups: CKD $60-89 \mathrm{ml} / \mathrm{min} / 1.73 \mathrm{~m}^{2}$ and CKD $\geq 90 \mathrm{ml} / \mathrm{min} / 1.73 \mathrm{~m}^{2}$ but only 8 have $C K D \geq 90 \mathrm{ml} / \mathrm{min} / 1.73 \mathrm{~m}^{2}$.

To confirm these results, we also evaluated the correlation between both assays with analysis of the quantitative results of $\mathrm{k}-\mathrm{FLC}, \lambda$-FLC and FLC $\mathrm{k} / \lambda$ ratio (using PassingBablock regression and Pearson correlation coefficient $r$ ) when glomerular renal function 
was evaluated with MDRD formulae. We then evaluated the qualitative concordance of the two tests (Cohen's kappa coefficient) when GFR was evaluated with MDRD formulae. Results are comparable to those presented above (data not shown).

\section{FLC evolution and patient's follow-up}

To evaluate FLC evolution measured with both assays in patient's follow-up, 41 patients were selected with at least 6 consecutive serum samples collected during the study period. Of these 41 patients, 19 had normal FLC ratio for both assays during follow-up and 22 presented an abnormal FLC ratio with Freelite $^{\mathrm{TM}}$ and $\mathrm{N}$ Latex with an objective monoclonality, corresponding to 155 samples. Seven patients had monoclonal $\lambda$-FLC (P6P9-P12-P15-P16-P18-P19) and 15 patients had monoclonal k-FLC. Of these 22 patients, 14 had no response or progressive disease, 5 presented PR and 3 presented VGPR, with the two assays. Thus, in patient's follow-up, both assays allowed similar t classification of the patient's response to treatment. Figure 2 shows the trend of $K / \lambda$ FLC ratio with Freelite $^{\mathrm{TM}}$ assay (grey line, left axis) and $\mathrm{N}$-Latex assay (black line, right axis) for 22 patients who were sampled at least 6 times. It can be seen that, for 11 patients, Freelite ${ }^{\mathrm{TM}}$ FLC ratio and N Latex FLC ratio showed a parallel evolution (P1, P4, P5, P7, P8, P9, P10, P11, P12, P13, and P21). For 5 patients (P3, P14, P17, P20 and P22), few discrepancies were observed with no clinical impact. These discrepancies are linked to the very low concentration of uninvolved FLC, which was systematically $\lambda$-FLC. Of note, as previously described, the variation coefficient, which could increase to $11.2 \%$ for low values of $\lambda$-FLC, is responsible for huge variations, explaining the variations in the ratios. For patient 6 (P6) we observed a discrepancy in the FLC ratios, there were no discordances in thek-FLC and $\lambda$-FLC absolute values. However, a few significant discrepancies were observed with 4 
patients: no response or progressive disease with Freelite $^{\mathrm{TM}}$ and partial response with $\mathrm{N}$ Latex (3 cases, P15-P18-P19), no response or progressive disease with $\mathrm{N}$ Latex and partial response with Freelite ${ }^{\mathrm{TM}}$ (1 case, P2) (Figure 2). As a result of repeated serum samples, however, these discrepancies did not influence evaluation of patient's response. Patient $16(\mathrm{P} 16)$ was particularly interesting because during follow-up, Freelite ${ }^{\mathrm{TM}}$ FLC ratio was within the normal range, whereas $N$ Latex FLC ratio and $\lambda$-FLC measured with $N$ Latex suggested a monoclonal $\lambda$-FLC (Figure 2). He was diagnosed with an IgG lambda multiple myeloma in January 2012.

These differences in absolute concentrations illustrated that this evaluation (especially with FLC assays) needs at least two consecutive analyses to be interpreted. For example, figure 3 illustrates one patient's follow-up (Patient 18): between 6/26/2012 an 7/24/2012, $\lambda$ FLC measured with Freelite ${ }^{\mathrm{TM}}$ assay increased from 260 to $272 \mathrm{mg} / \mathrm{L}$ (+4.6\%) while $\lambda$-FLC measured with N Latex assay decreased from 282 to $146 \mathrm{mg} / \mathrm{L}(-48.2 \%)$ (Figure 3). When monitoring the disease with $\mathrm{dFLC}$ ( $\mathrm{dFLC}=$ involved FLC - uninvolved FLC), these results indicated a stable condition with Freelite ${ }^{\mathrm{TM}}$ (slight increase of 1.9\%) and a partial response (-53.1\%) with N Latex FLC. This partial response was also found with Freelite ${ }^{\mathrm{TM}}$ in the next sample.

\section{Discussion}

Serum protein electrophoresis, immunofixation and FLC measurement are now the gold standard for diagnosis and monitoring of patients with monoclonal gammopathy. In 2001, the Binding Site Company has developed the first quantitative assay (Freelite ${ }^{\mathrm{TM}}$ assay) which is an adaptable turbidity measurement and nephelemetry method based on polyclonal antibodies ${ }^{8}$. This assay was the only commercially available assay when 
recommendations for evaluation and management of multiple myeloma by the international Myeloma Working Group were established. A second assay, N Latex developed by Siemens in 2011, employs only nephelemetry and uses a mixture of monoclonal antibodies. More recently, the Seralite ${ }^{\circledR}$ dual $k$ and $\lambda$ assay was developed by Abingdon Health, York, UK: this is a rapid and portable diagnostic device enabling the simultaneous quantification measurement of serum $\mathrm{k}$ and $\lambda \mathrm{FLC}$, but a very few data are available concerning this assay. ${ }^{17}$.

Many studies have been carried out to compare results of Freelite ${ }^{\mathrm{TM}}$ and $\mathrm{N}$ Latex assays, and they have concluded that, besides analytical limitations, numerical results are not equivalent but overall show a good match, with slightly lower correlations for $\lambda$-FLC and FLC K/入 ratio ${ }^{10-14,17,23-25}$. As FLC are cleared via glomerular filtration, FLC levels increase with decreasing GFR. Recently, Jacobs et al. demonstrated that N Latex FLC ratio in CKD patients without gammopathy seem to be eGFR independent, with a parallel increase of $\mathrm{K}$ FLC and $\lambda$-FLC with decreasing GFR ${ }^{19}$. In this study, N Latex K-FLC and Freelite ${ }^{\mathrm{TM}}{ }_{\mathrm{K}}$-FLC were similar in CKD patients while N Latex $\lambda$-FLC provided higher results than Freelite ${ }^{\mathrm{TM}} \lambda$ FLC. As a result, FLC $\mathrm{K} / \lambda$ ratio increases with decreasing GFR with Freelite $^{\mathrm{TM}}$, which explains the necessity of a specific reference range for CKD patients with Freelite ${ }^{\mathrm{TM}}$. In contrast, with $\mathrm{N}$ Latex, the $\mathrm{FLC}$ ratio reference range remains unaffected over all stages of CKD. Moreover, Kennard et al. demonstrated in a cohort of 112 haemodialysis patients with polyclonal FLC, that $\lambda$-FLC levels were higher with the N-Latex assay than with Freelite $^{\mathrm{TM}}$ assay and this excess of $\lambda$-FLC persisted post-dialysis but slightly attenuated ${ }^{25}$. However, all these results were obtained in CKD patients without monoclonal gammopathy. In this context, we evaluated the concordance and the correlation between both FLC assays in patients with or without gammopathy taking into account the impact of kidney disease. Our results showed a good correlation between the two assays ( $>0.90)$, 
when considering absolute values of FLC and FLC ratio from the whole cohort of 1215 samples. In samples with CKD and without monoclonal gammopathy ( $n=167)$, contrary to Jacobs et al. and Kennard et al., we observed a significant difference between the 2 assays for $\mathrm{k}-\mathrm{FLC}(\mathrm{p}=0.006$, student test), $\lambda$-FLC $(p<0.0001$, student test) and $\mathrm{FLC} \mathrm{k} / \lambda$ ratio $(p<0.0001 \text {, student test })^{19,25}$.

To date, our results allowed the conclusion that both FLC assays presented a good correlation, especially when values are in the reference range of each method. Nevertheless, two other population groups became apparent: a group of values with low concentrations of FLC (1 to $7 \mathrm{mg} / \mathrm{L}$ ) for which $\mathrm{N}$ Latex FLC assay found higher results than Freelite $^{\mathrm{TM}}$ assay. In contrast, we observed a group of values with high FLC concentrations (above $100 \mathrm{mg} / \mathrm{L}$ ) for which Freelite ${ }^{\mathrm{TM}}$ assay resulted in slightly higher results than $\mathrm{N}$ Latex FLC. This latter group could be a progressive deviation from the difference between the two assays. This mismatch of assays in low values does not a necessarily have a clinical impact on the detection of monoclonal components because values are then sufficiently low to exclude the presence of a monoclonal FLC or sufficiently high to confirm their presence. To explain these results, hypotheses regarding the formation of FLC polymers in certain cases of monoclonal protein synthesis have already been formulated. Recently, Di Noto et al. argued that FLC polymers influence the immunometric quantification ${ }^{10}$. They highlighted that the two methods behave differently in monoclonal samples, particularly at higher concentrations. This confirms that a monoclonal protein, depending on its biochemical/biophysical characteristics could present different stoichiometric interactions with different test antibodies ${ }^{10}$. This observation is usually related with the presence of FLC dimers (and sometimes multimers) in mismatching sera which present a probably modified reactivity with antibody detection and light diffraction properties ${ }^{16,26}$. Nevertheless, to date no direct relation has been found and this hypothesis of 
overestimation for high concentrations does not explain the mismatch observed at low concentrations. A possible relation between the nature of antibodies and implicated epitopes could be formulated. Thus, the monoclonal antibodies applied in N Latex FLC assay present better specificity for polyclonal FLC detection because they target an epitope found in all normal FLC with a strong affinity.

When considering renal function, our results allowed the conclusion that there was good correlations between both assays, irrespective of the renal impairment stage. In our study, $\mathrm{N}$ Latex FLC method detected higher concentration $\lambda$-FLC and $\mathrm{k}-\mathrm{FLC}$, contrary to Jacobs et al. who found no difference in K-FLC concentrations between the two assays ${ }^{19}$. Our results could be explained by the studied population, mainly consisting of patients with gammopathy (368 patients/455, 81\% and 876 samples/1215, 72\%). When we interpreted independently patients with or without gammopathy, we observed that patients with monoclonal gammopathy are not distributed differently across the different panels of renal failure stages: the correlation between both assays seems to be better in patients with monoclonal gammopthy than in patients without monoclonal gammopathy.

When comparing the interpretation of the FLC ratio, $12.5 \%$ discrepancies remained between the two assays and the rate was independent of the renal failure stage. In monoclonal gammapthy samples, we found $15 \%$ discordant results, whose $23 \%$ in eGFR $>60 \mathrm{ml} / \mathrm{min} / 1.73 \mathrm{~m}^{2}$ and $12 \%$ in $\mathrm{eGFR}<60 \mathrm{ml} / \mathrm{min} / 1.73 \mathrm{~m}^{2}$. For these discordant results, neither assay was better than the other and results should be interpreted taking into account clinical data. To date, the two tests could be used in patients with renal impairment, since correlation between both assays is good even with patients with severe renal failure.

For follow-up patients, our study demonstrated generally a good correlation between the 
two assays by indicating an identical response to treatment. However, it is necessary to interpret results taking into account absolute FLC values, FLC ratio and dFLC when applicable. Nevertheless, few discrepancies remained between both tests and the reason for these differences is still unknown. We confirmed that quantitative discrepancies remain between the two assays and the methods are not interchangeable in the follow-up of monoclonal gammopathy ${ }^{12,16,23}$.

\section{Conclusion}

To conclude, in view of currently published data and results of this study, we can confirm a good correlation between the two FLC assays, even in patients with renal failure ${ }^{15,19,25}$. However, results in absolute values of both assays remain comparable but not numerically identical, and the results of one assay cannot be considered to be better than the other. Due to the differences observed between the two assays, they cannot be uses indiscriminately. When a laboratory wants to change from one test to another, it is necessary to use both tests for an approximately a 6 month period of transition to avoid misinterpretation of results.

\section{Clinical Practice Points}

- Free light chains (FLC) assays play an important role in diagnosis and follow-up of plasma cell dyscrasia.

- Two assays are available: Freelite ${ }^{\mathrm{TM}}$ (Binding Site) and N-Latex FLC (Siemens).

- An extended Freelite ${ }^{T M}$ FLC ratio reference range has been defined for patients with chronic kidney disease (CKD) whilst N Latex FLC ratio was described as being eGFR independent. 
- We evaluated concordance and correlation between the two assays according to renal failure stage and for evaluation of response.

- Our results demonstrated a good correlation between both assays, irrespective of the renal failure stage (Pearson correlation coefficient >0.90). However, there remained $12.5 \%$ of discrepancy in the interpretation of FLC ratio between the two assays. The rate of discrepancies is independent of renal failure stage

- Our results suggest that the two assays allow similar classification of the patient's response to treatment.

- Neither of the assays is better than the other and results must be interpreted taking clinical data into consideration.

- The two assays cannot be interchanged. When a laboratory wants to change from one test to the other, we suggest using both tests for an approximately 6 month transition period to avoid misinterpretation of results.

\section{Acknowledgements}

The authors thank Siemens Healthcare Diagnosis for technical support for providing reagents, in particular Carola Wagner and Jean-Denis Berville. We also thank Dr Lucienne Guenet for her involvement in this study and Phillip Jordan for his proof reading. 


\section{References}

1. Rajkumar SV. Myeloma today: Disease definitions and treatment advances. Am J Hematol. 2016;91(1):90-100.

2. Rajkumar SV, Landgren $\mathrm{O}$, Mateos M-V. Smoldering multiple myeloma. Blood. 2015;125(20):3069-3075.

3. Durie BGM, Miguel JFS, Blade J, Rajkumar SV. Clarification of the definition of complete response in multiple myeloma. Leukemia. 2015;29(12):2416-2417.

4. Rao M, Lamont JL, Chan J, et al. Serum Free Light Chain Analysis for the Diagnosis, Management, and Prognosis of Plasma Cell Dyscrasias: Future Research Needs: Identification of Future Research Needs From Comparative Effectiveness Review No. 73. Rockville (MD): Agency for Healthcare Research and Quality (US); 2012. http://www.ncbi.nlm.nih.gov/books/NBK137788/. Accessed March 7, 2016.

5. Dispenzieri A, Kyle R, Merlini G, et al. International Myeloma Working Group guidelines for serum-free light chain analysis in multiple myeloma and related disorders. Leukemia. 2009;23(2):215-224.

6. Larsen JT, Kumar SK, Dispenzieri A, Kyle RA, Katzmann JA, Rajkumar SV. Serum free light chain ratio as a biomarker for high-risk smoldering multiple myeloma. Leukemia. 2013;27(4):941-946.

7. Rajkumar SV, Dimopoulos MA, Palumbo A, et al. International Myeloma Working Group updated criteria for the diagnosis of multiple myeloma. Lancet Oncol. 2014;15(12):e538-548.

8. Bradwell AR, Carr-Smith HD, Mead GP, et al. Highly sensitive, automated immunoassay for immunoglobulin free light chains in serum and urine. Clin Chem. 2001;47(4):673-680.

9. te Velthuis $\mathrm{H}$, Knop I, Stam P, et al. N Latex FLC - new monoclonal high-performance assays for the determination of free light chain kappa and lambda. Clin Chem Lab Med. 2011;49(8):1323-1332.

10. Di Noto G, Cimpoies E, Dossi A, et al. Polyclonal versus monoclonal immunoglobulinfree light chains quantification. Ann Clin Biochem. 2015;52(Pt 3):327-336.

11. Sasson SC, McGill K, Wienholt L, et al. Comparison of the Freelite serum free light chain (SFLC) assay with serum and urine electrophoresis/immunofixation and the $\mathrm{N}$ Latex FLC assay. Pathology (Phila). 2015;47(6):564-569.

12. Kim H-S, Kim HS, Shin K-S, et al. Clinical comparisons of two free light chain assays to immunofixation electrophoresis for detecting monoclonal gammopathy. BioMed Res Int. 2014;2014:647238.

13. Lock RJ, Saleem R, Roberts EG, et al. A multicentre study comparing two methods for serum free light chain analysis. Ann Clin Biochem. 2013;50(Pt 3):255-261. 
14. Daval S, Tridon A, Mazeron N, Ristori J-M, Evrard B. Risk of antigen excess in serum free light chain measurements. Clin Chem. 2007;53(11):1985-1986.

15. Jacobs JFM, Tate JR, Merlini G. Is accuracy of serum free light chain measurement achievable? Clin Chem Lab Med CCLM. 2015;54(6):1021-1030..

16. Caponi L, Franzini M, Koni E, Masotti S, Petrini M, Paolicchi A. Discrepancy between FLC assays: only a problem of quantification? Clin Chem Lab Med. 2016. doi:10.1515/cclm-2015-1262.

17. te Velthuis $\mathrm{H}$, Drayson $\mathrm{M}$, Campbell JP. Measurement of free light chains with assays based on monoclonal antibodies. Clin Chem Lab Med. 2016;54(6):1005-1014.

18. Gonsalves WI, Leung N, Rajkumar SV, et al. Improvement in renal function and its impact on survival in patients with newly diagnosed multiple myeloma. Blood Cancer J. 2015;5:e296.

19. Hutchison CA, Harding S, Hewins $P$, et al. Quantitative assessment of serum and urinary polyclonal free light chains in patients with chronic kidney disease. Clin J Am Soc Nephrol CJASN. 2008;3(6):1684-1690.

20. Jacobs JFM, Hoedemakers RMJ, Teunissen E, Te Velthuis H. N Latex FLC serum free light-chain assays in patients with renal impairment. Clin Chem Lab Med. 2014;52(6):853-859.

21. Levey AS, Stevens LA, Schmid $\mathrm{CH}$, et al. A new equation to estimate glomerular filtration rate. Ann Intern Med. 2009;150(9):604-612.

22. Pretorius $\mathrm{CJ}$, Klingberg $\mathrm{S}$, Tate $\mathrm{J}$, Wilgen $\mathrm{U}$, Ungerer JPJ. Evaluation of the $\mathrm{N}$ Latex FLC free light chain assay on the Siemens BN analyser: precision, agreement, linearity and variation between reagent lots. Ann Clin Biochem. 2012;49(Pt 5):450455.

23. Hoedemakers RMJ, Pruijt JFM, Hol S, et al. Clinical comparison of new monoclonal antibody-based nephelometric assays for free light chain kappa and lambda to polyclonal antibody-based assays and immunofixation electrophoresis. Clin Chem Lab Med. 2012;50(3):489-495.

24. Carr-Smith HD, Jenner EL, Evans JAR, Harding SJ. Analytical issues of serum free light chain assays and the relative performance of polyclonal and monoclonal based reagents. Clin Chem Lab Med CCLM. 2016;54(6):997-1003.

25. Kennard A, Hawley C, Tate J, et al. Comparison of Freelite ${ }^{\mathrm{TM}}$ and $\mathrm{N}$ Latex serum free light chain assays in subjects with end stage kidney disease on haemodialysis. Clin Chem Lab Med. December 2015.

26. Kaplan B, Livneh A, Sela B-A. Immunoglobulin free light chain dimers in human diseases. ScientificWorldJournal. 2011;11:726-735.. 


\section{Figures and Tables legends}

Figure 1 Freelite $^{\mathrm{TM}}$ assay vs $\mathrm{N}$ Latex assay for the comparison of $\mathrm{K}$-FLC, $\lambda$-FLC and FLC ratio in 1215 samples (A) and in chronic kidney disease patients (B: patients with CKD>60 $\mathrm{ml} / \mathrm{min} / 1.73 \mathrm{~m}^{2}$ ( $\left.\mathrm{n}=144\right)$; C: patients with $31<\mathrm{CKD}<60 \mathrm{ml} / \mathrm{min} / 1.73 \mathrm{~m}^{2}(\mathrm{n}=428)$; D: patients with $15<C K D<30 \mathrm{ml} / \mathrm{min} / 1.73 \mathrm{~m}^{2}(\mathrm{n}=154) ; \mathrm{E}$ : patients with $\mathrm{CKD}<15 \mathrm{ml} / \mathrm{min} / 1.73 \mathrm{~m}^{2}$ $(n=92)$.

Parallel dotted lines indicate the reference ranges for the specific assays. The solid line indicates the Passing Bablock regression equation and the dotted line indicates the $y=x$ axes.

Black plots represent patients with monoclonal gammopathy (MG+) and red plots those without monoclonal gammopathy (MG-)

Under each figure is shown the Passing-Bablock regression and Pearson correlation factor for all samples and samples with (MG+) or without (MG-) monoclonal gammopathy. 

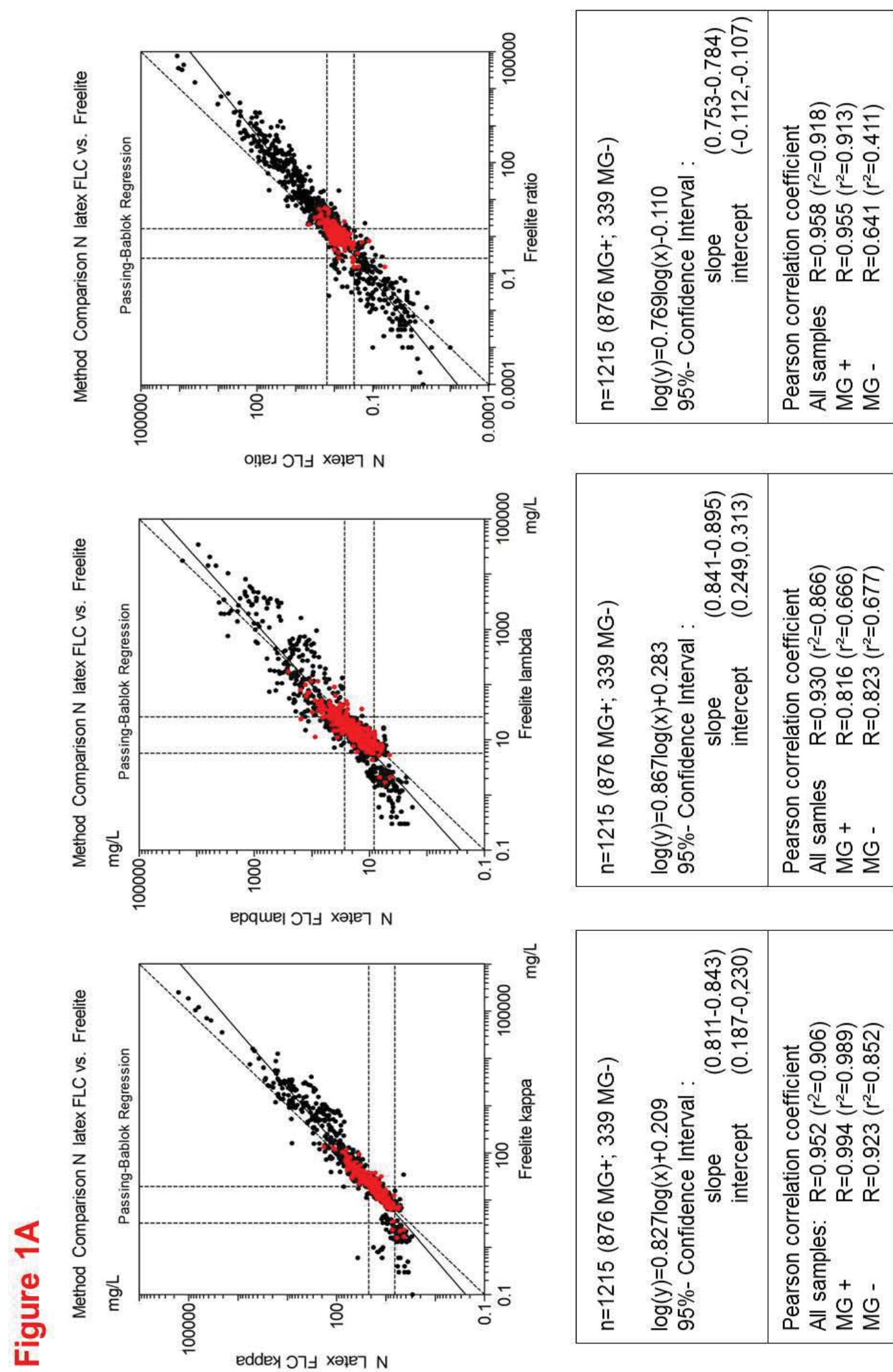

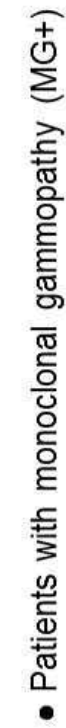



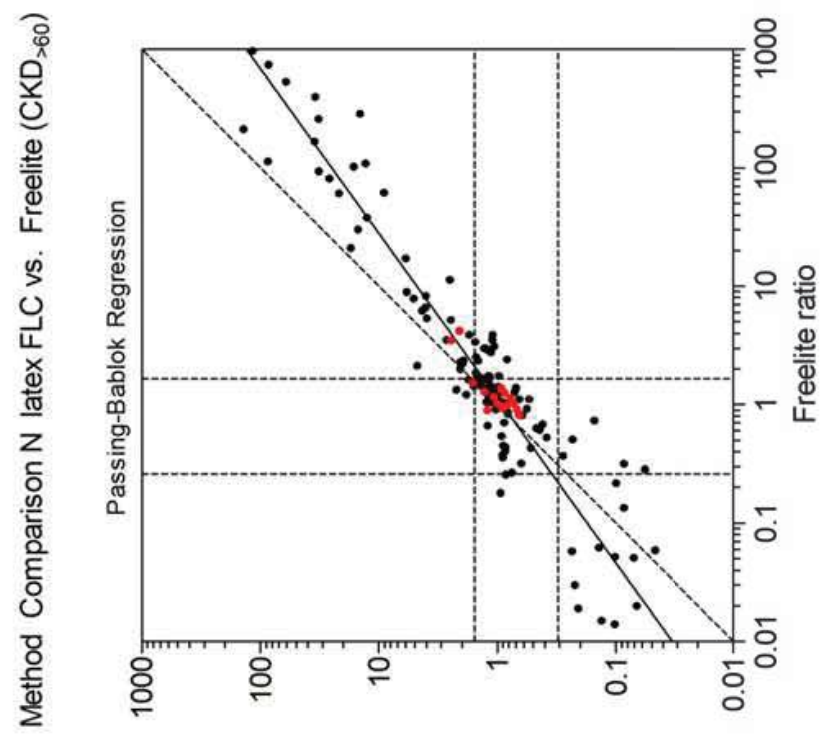

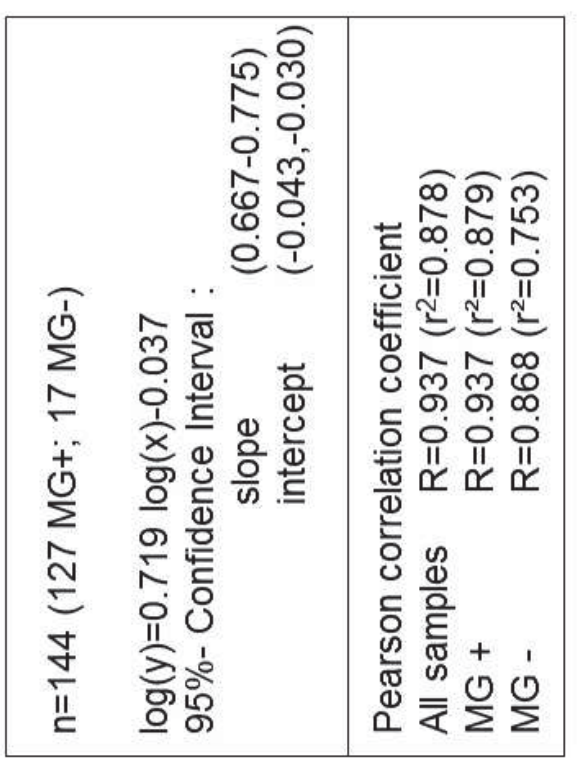

ำฺ วา хәฺอา N
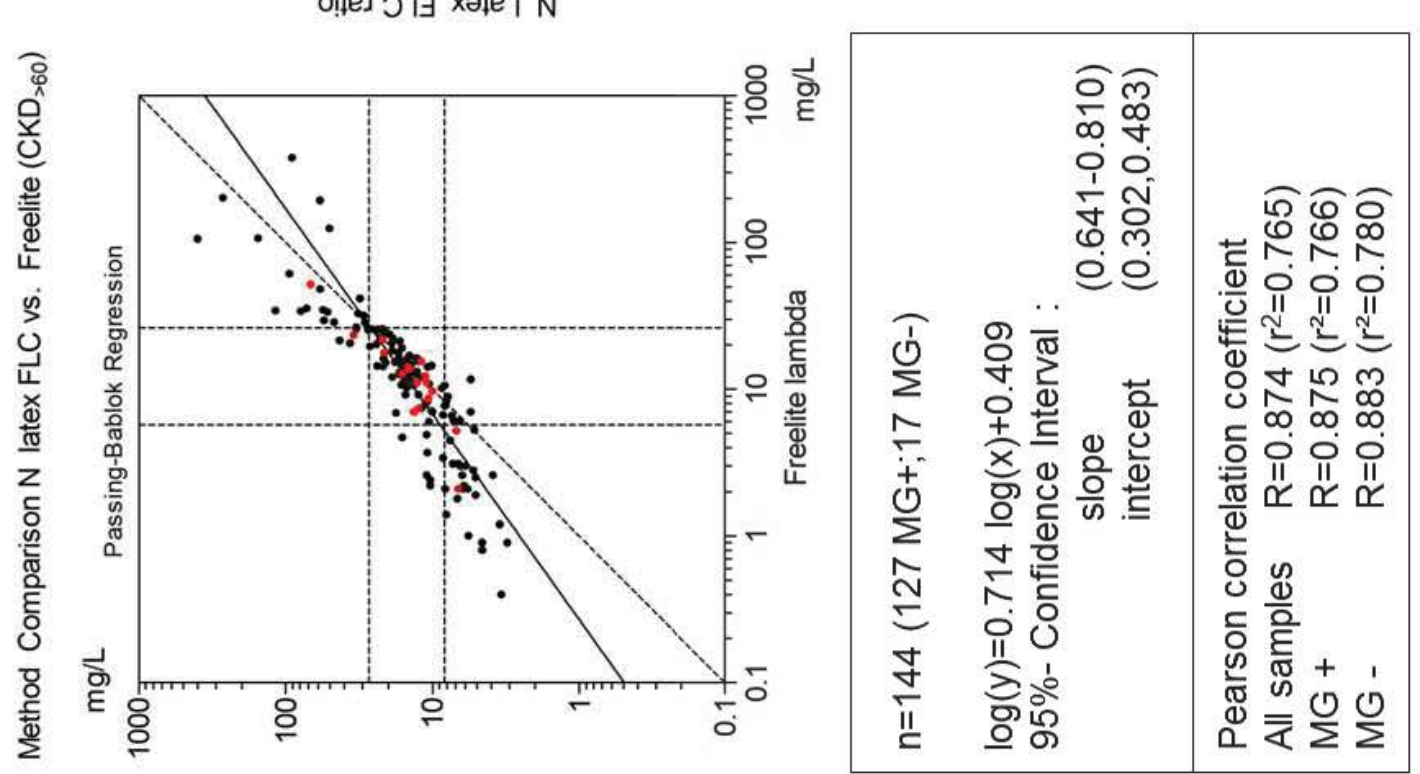

ерque วาษ хәฺеา N
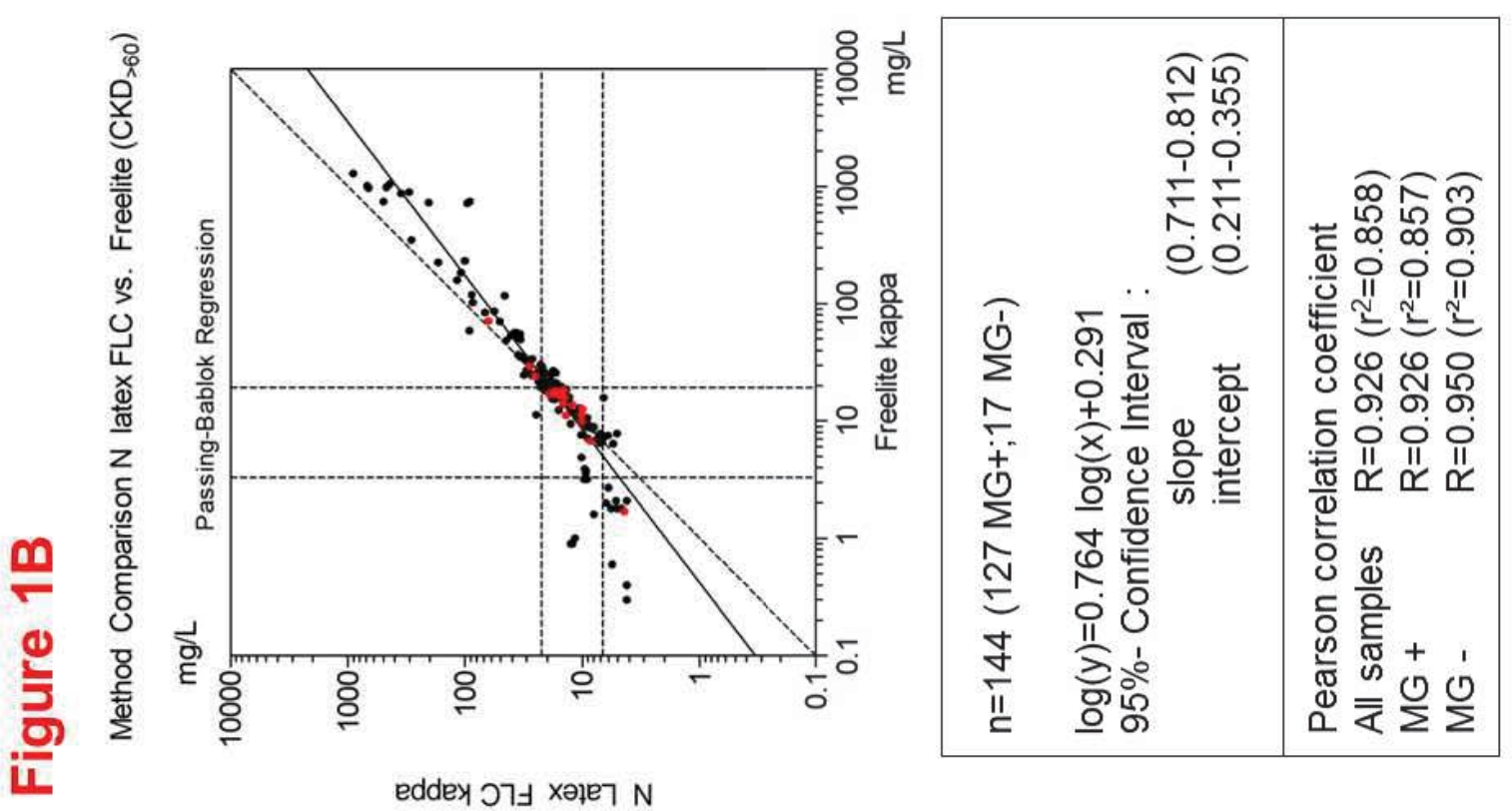

eddex วา хәฺฺ 


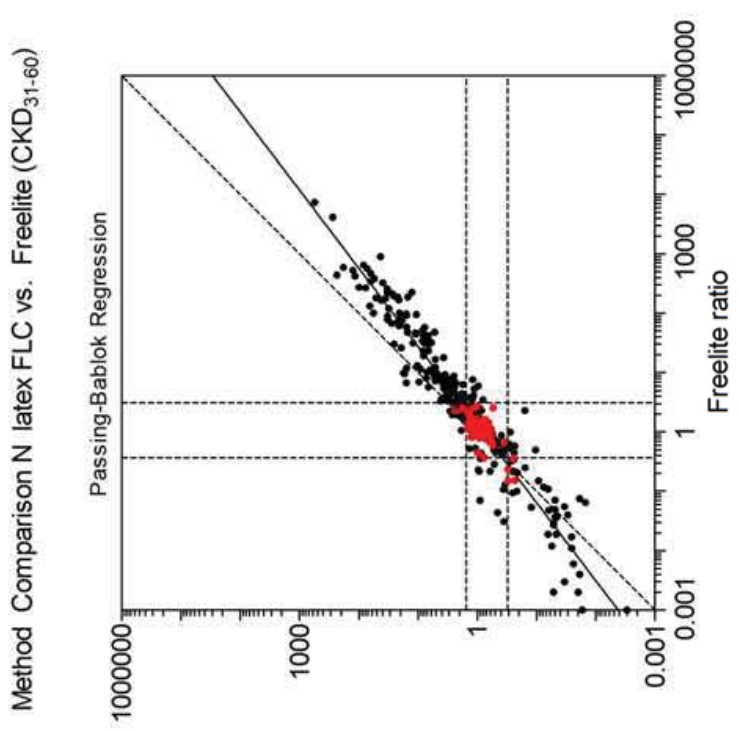

ำe נ
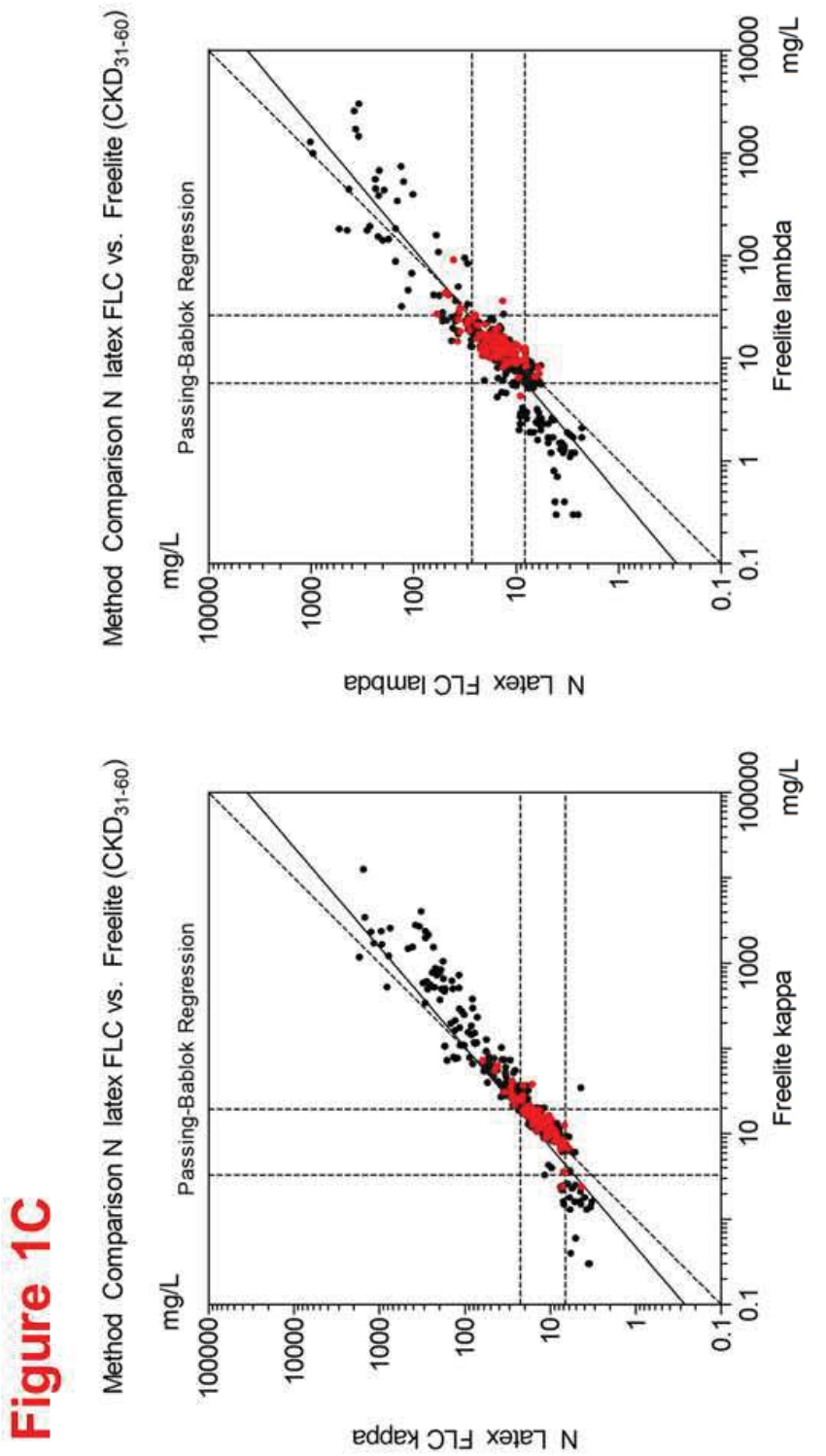

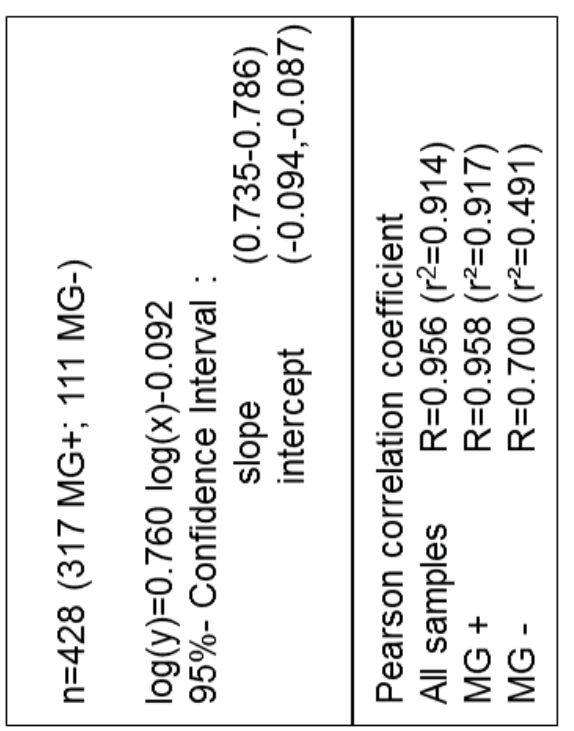

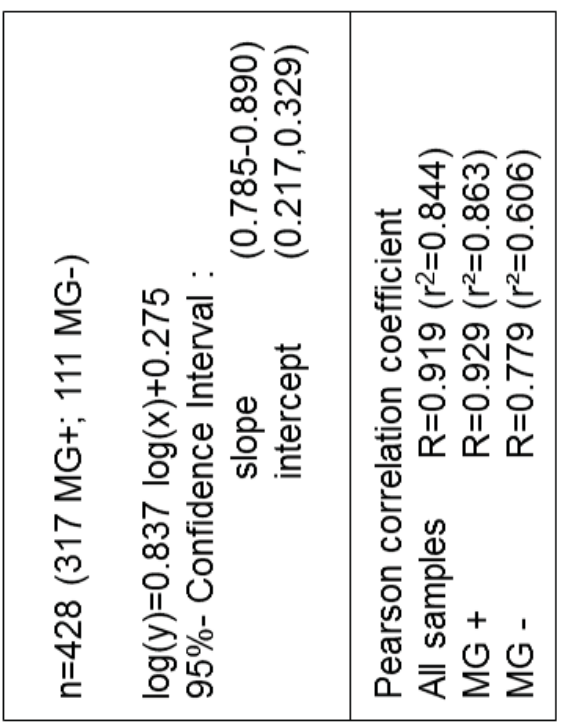



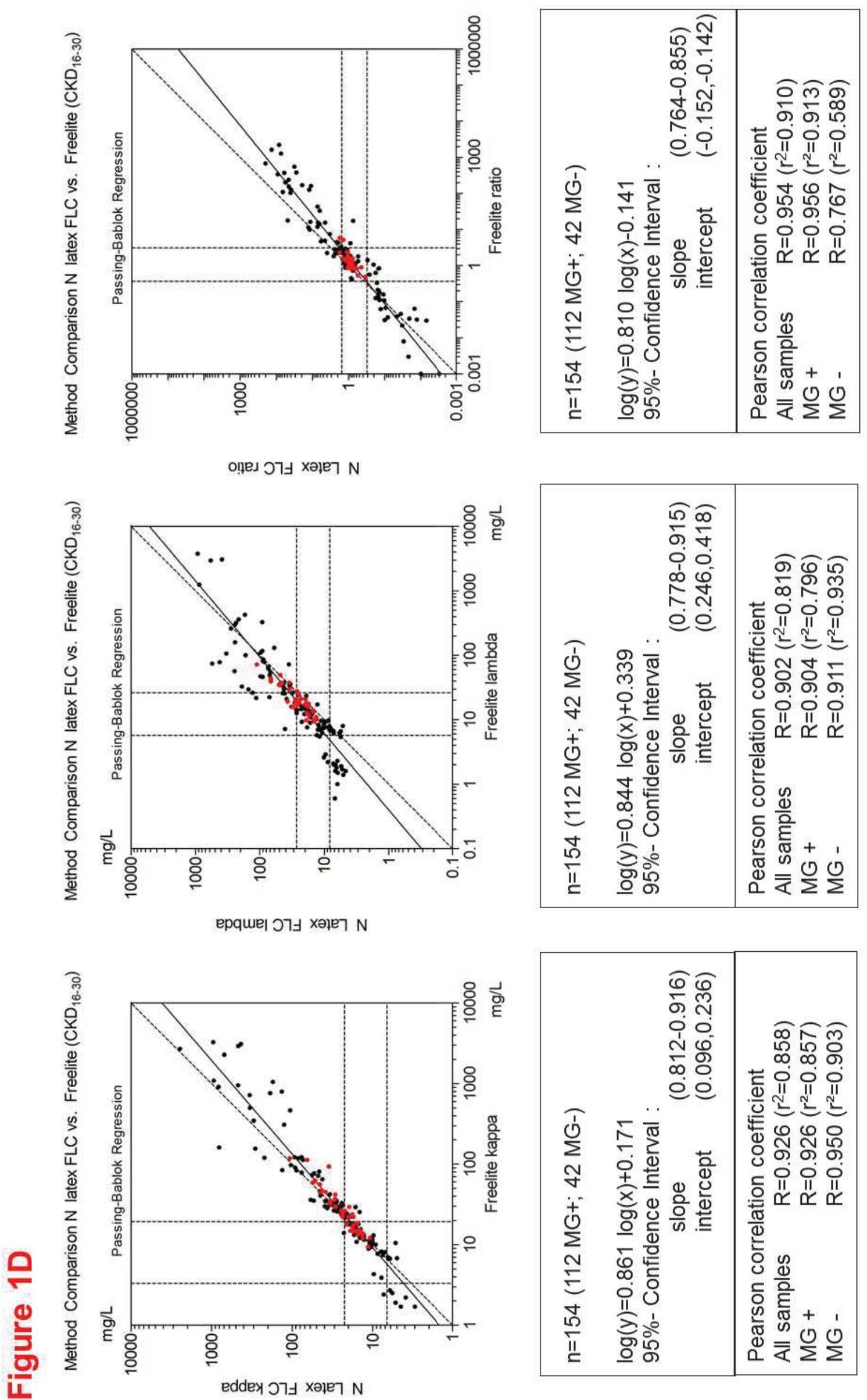

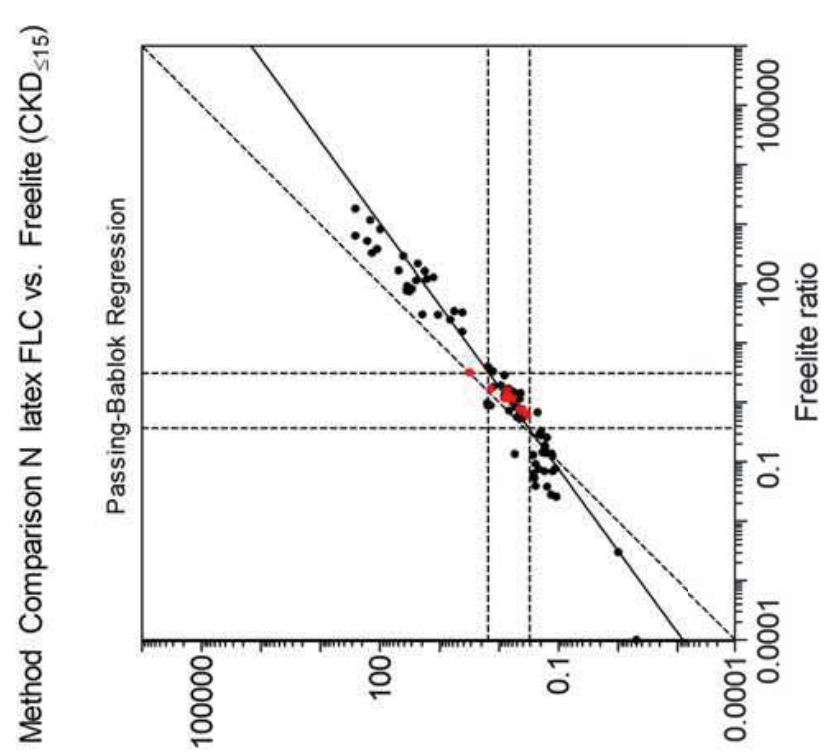

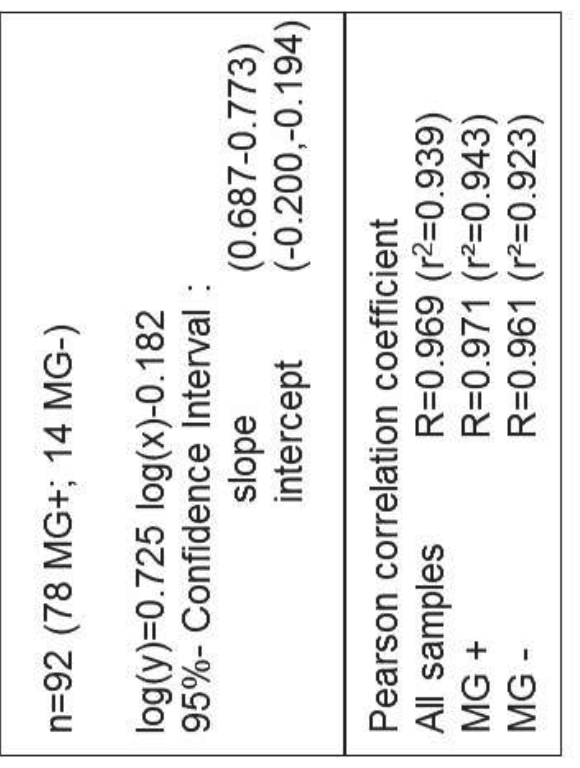
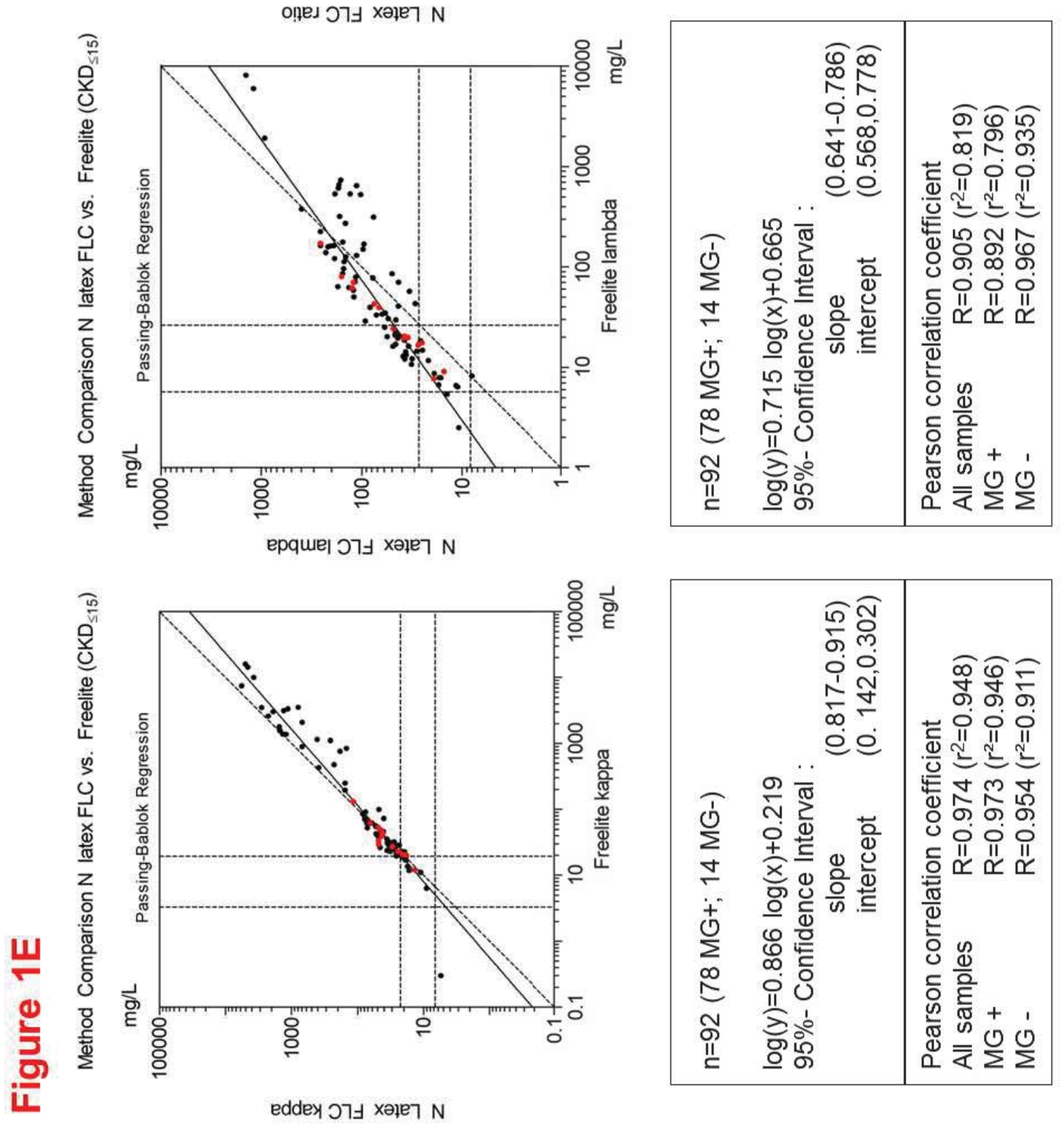
Figure 2 Follow-up of the Freelite ${ }^{\mathrm{TM}}$ FLC-ratio and N-Latex FLC- of the 22 patients with an abnormal FLC. Graphs represent the trend of $\mathrm{K} / \lambda \mathrm{FLC}$ ratio with Freelite ${ }^{\mathrm{TM}}$ assay (grey line, left axis) and N-Latex assay (black line, right axis) for 22 patients who were sampled at least 6 times. Patients with a star are those having a significant clinical discrepancy in their care, which is framed on the graph. 

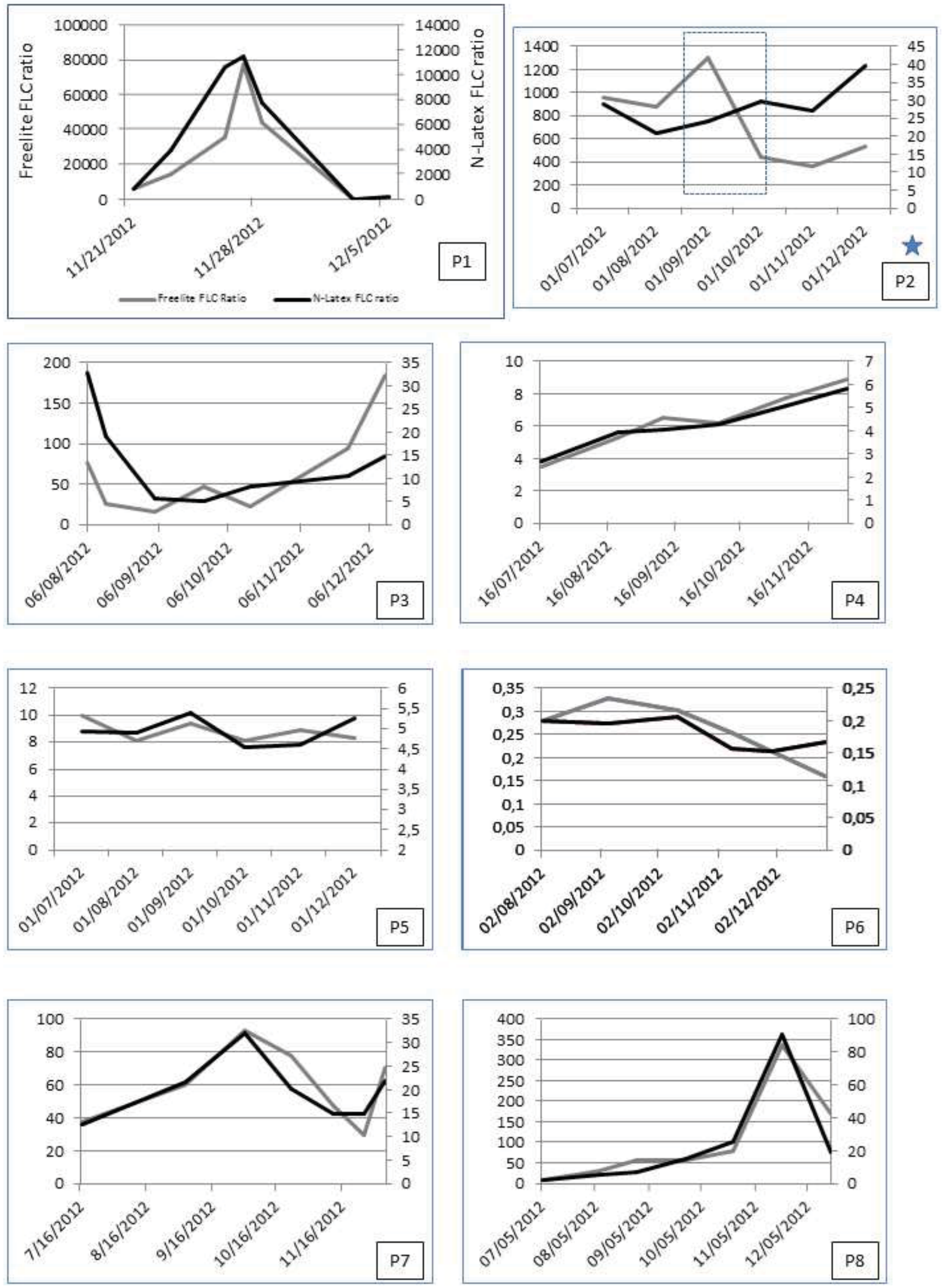

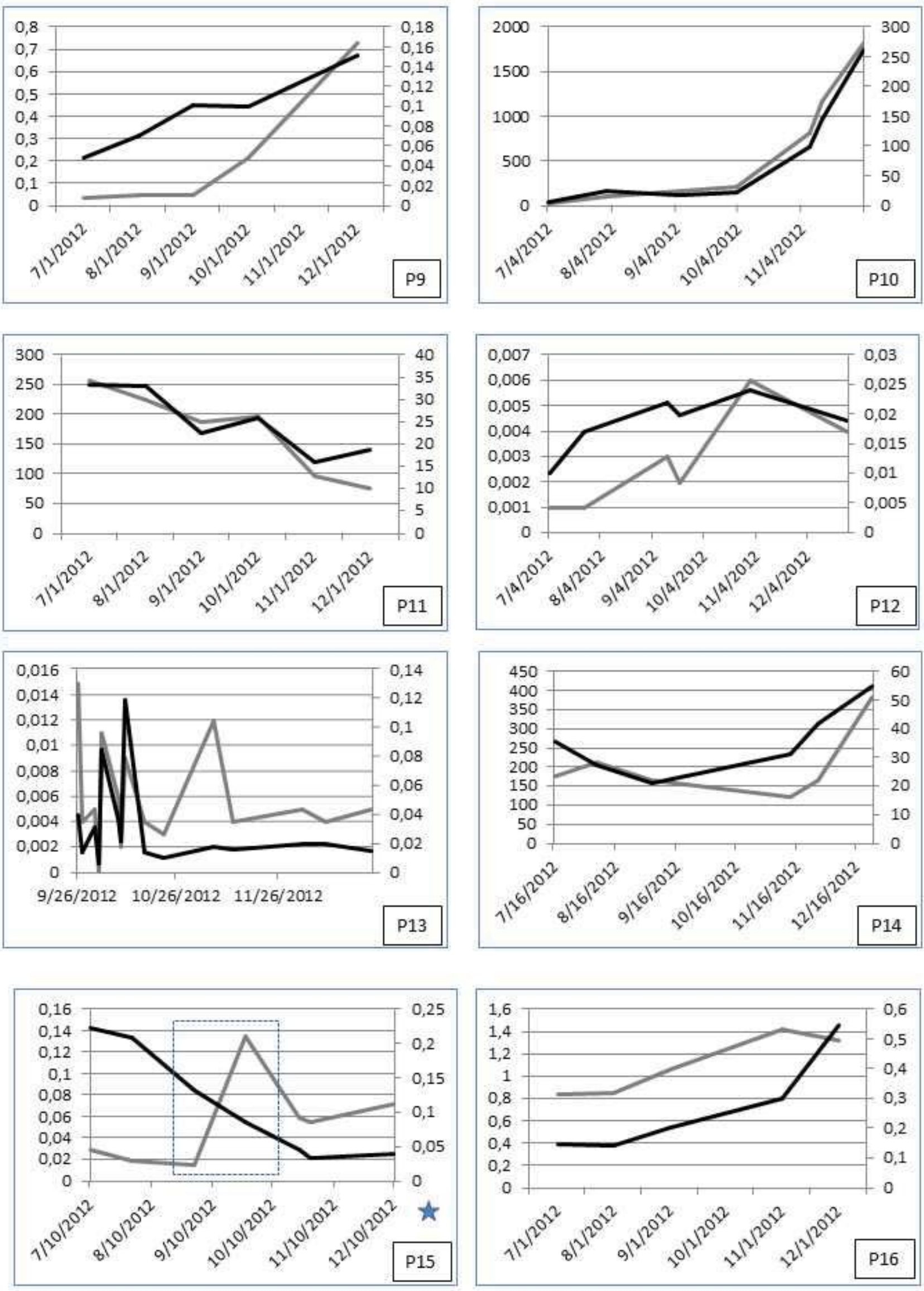

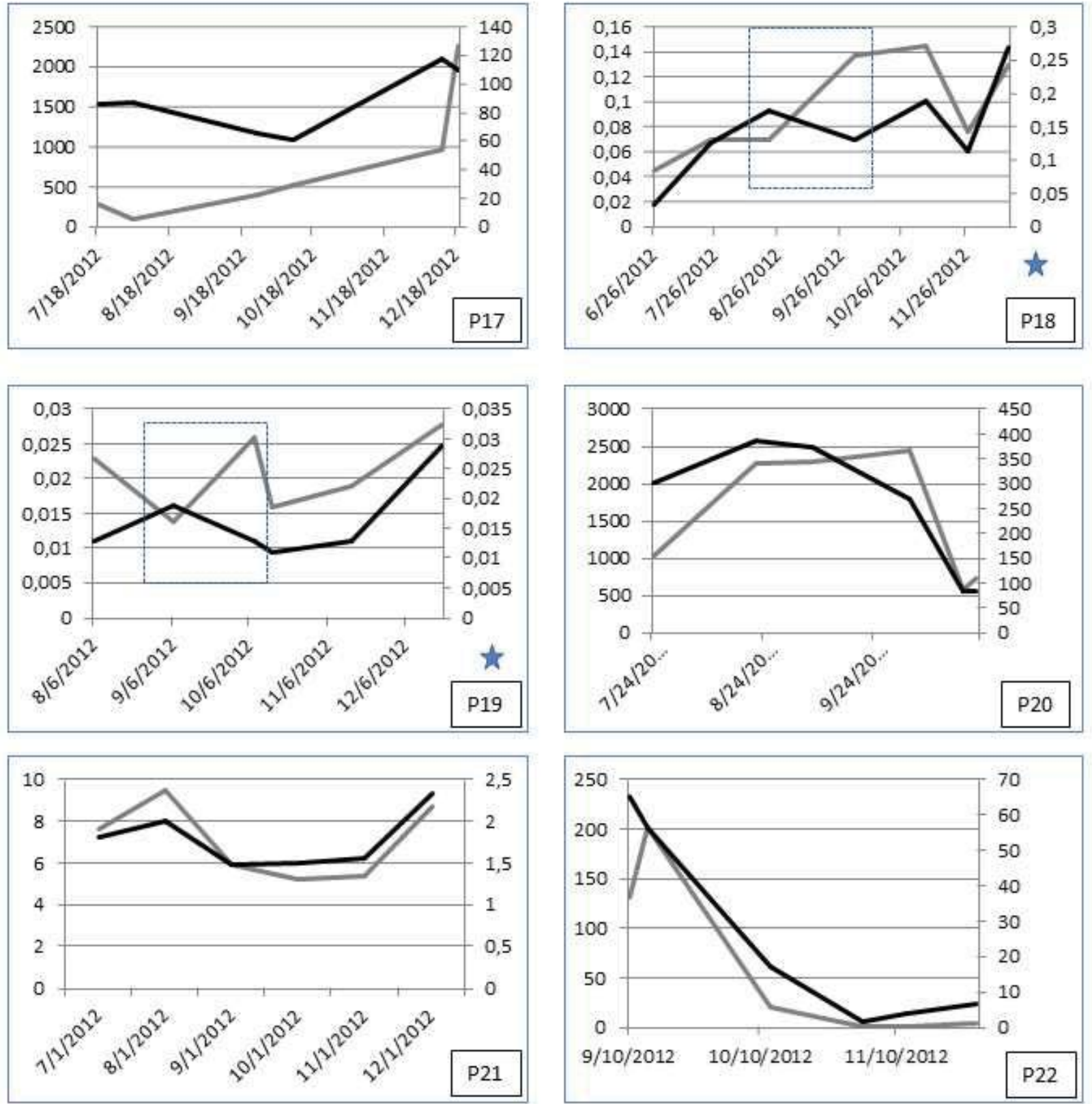
Figure 3 Example of one follow up for whom neither assay allowed similar classification this patient's treatment response. The graph represents the trend of $\mathrm{k}-\mathrm{FLC}, \lambda-\mathrm{FLC}$ and $\mathrm{k} / \lambda$ FLC ratio measured with Freelite ${ }^{\mathrm{TM}}$ and N Latex FLC assays. 


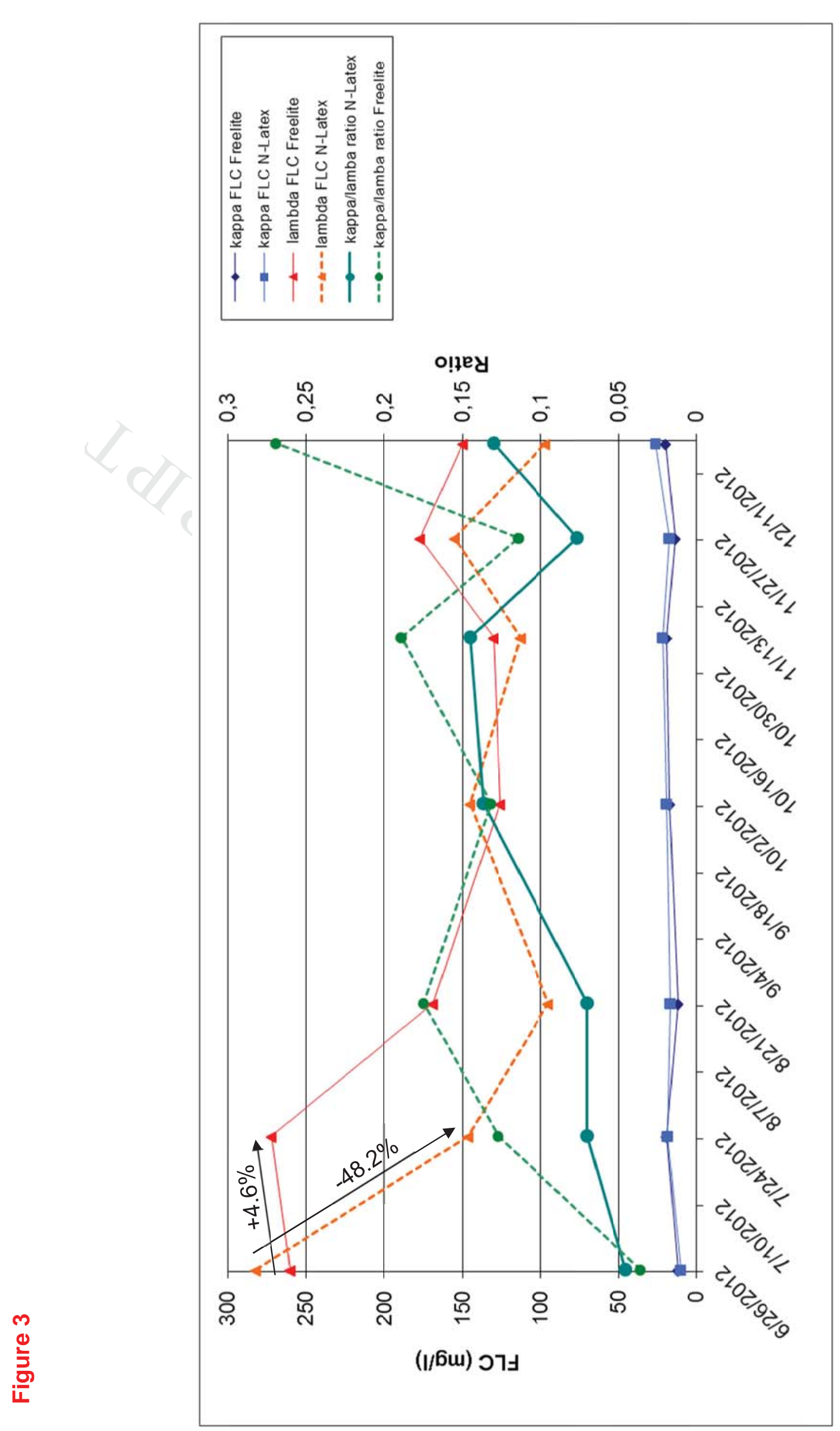


Table 1. Concordance of FLC ratio clinical interpretation between Freelite ${ }^{\mathrm{TM}}$ and $\mathrm{N}$ Latex FLC assays. Results were presented according to the reference range proposed by manufacturer.

A

$\mathrm{CKD}>60 \mathrm{ml} / \mathrm{min} / 1.73 \mathrm{~m} 2$ $\mathrm{n}=144$

\begin{tabular}{|c|l|l|l|l|}
\cline { 3 - 5 } \multicolumn{2}{c|}{} & $<0.26$ & $0.26-1.65$ & $>1.65$ \\
\cline { 2 - 5 } \multicolumn{2}{c|}{} & $\mathrm{n}$ & $\mathrm{n}$ & $\mathrm{n}$ \\
\hline \multirow{3}{*}{$\begin{array}{l}\text { N-Latex } \\
\text { FLC ratio }\end{array}$} & $<0.31$ & 12 & 5 & 0 \\
\cline { 2 - 5 } & $0.31-1.56$ & 2 & 66 & 18 \\
\cline { 2 - 5 } & $>1.56$ & 0 & 5 & 36 \\
\hline
\end{tabular}

Cohen's kappa coefficient 0.6323

B

$\mathrm{CKD}_{31-60 \mathrm{ml} / \mathrm{min} / 1.73 \mathrm{~m} 2}$ $n=428$

\begin{tabular}{|c|l|l|l|l|}
\hline \multirow{2}{*}{$\begin{array}{c}\text { N-Latex } \\
\text { FLC ratio }\end{array}$} & $<0.31$ & 40 & 7 & $\mathrm{n}$ \\
\cline { 2 - 5 } & $0.31-1.56$ & 11 & 217 & 7 \\
\cline { 2 - 5 } & $>1.56$ & 0 & 23 & 123 \\
\hline
\end{tabular}

Cohen's kappa coefficient 0.802

C

$\mathrm{CKD}_{15-30 \mathrm{ml} / \mathrm{min} / 1.73 \mathrm{~m} 2}$ $n=154$

\begin{tabular}{|c|l|l|l|l|}
\multicolumn{2}{c|}{$n=154$} & \multicolumn{4}{c|}{ Freelite FLC ratio } \\
\cline { 3 - 5 } \multicolumn{2}{c|}{} & $<0.26$ & $0.37-3.1$ & $>1.65$ \\
\cline { 2 - 5 } \multicolumn{2}{c|}{} & $\mathrm{n}$ & $\mathrm{n}$ & $\mathrm{n}$ \\
\hline \multirow{3}{*}{$\begin{array}{c}\text { N-Latex } \\
\text { FLC ratio }\end{array}$} & $<0.31$ & 25 & 6 & 0 \\
\cline { 2 - 5 } & $0.31-1.56$ & 0 & 78 & 3 \\
\cline { 2 - 5 } & $>1.56$ & 0 & 8 & 34 \\
\hline
\end{tabular}

Cohen's kappa coefficient 0.8121

D

$\mathrm{CKD}_{<15 \mathrm{~m} / / \mathrm{min} / 1.73 \mathrm{~m} 2}$ $\mathrm{n}=92$

N-Latex

FLC ratio

\begin{tabular}{|l|l|}
\hline$<0.31$ & 26 \\
\hline $0.31-1.56$ & 1 \\
\hline$>1.56$ & 0 \\
\hline
\end{tabular}

\begin{tabular}{|l|l|l|}
\hline \multicolumn{3}{|c|}{ Freelite FLC ratio } \\
\hline$<0.26$ & $0.37-3.1$ & $>1.65$ \\
\hline $\mathrm{n}$ & $\mathrm{n}$ & $\mathrm{n}$ \\
\hline 26 & 1 & 0 \\
\hline 1 & 33 & 2 \\
\hline 0 & 3 & 26 \\
\hline
\end{tabular}

Cohen's kappa coefficient 0.8848 
Table 2. Concordance of FLC ratio clinical interpretation between Freelite ${ }^{\mathrm{TM}}$ and $\mathrm{N}$ Latex FLC assays considering the production of a monoclonal compound by the patient. Results were presented according to the reference range proposed by manufacturer.

A

$\mathrm{CKD}_{>60 \mathrm{~m} / \mathrm{min} / 1.73 \mathrm{~m}^{2}}$ with monoclonal gammopathy

\begin{tabular}{|c|c|c|c|c|}
\hline \multicolumn{2}{|l|}{$n=127$} & \multicolumn{3}{|c|}{ Freelite FLC ratio } \\
\hline & & $<0.26$ & $0.26-1.65$ & $>1.65$ \\
\hline & & $\mathrm{n}$ & $\mathrm{n}$ & $\mathrm{n}$ \\
\hline \multirow{3}{*}{$\begin{array}{l}\text { N-Latex } \\
\text { FLC ratio }\end{array}$} & $<0.31$ & 12 & 5 & 0 \\
\hline & $0.31-1.56$ & 2 & 52 & 18 \\
\hline & $>1.56$ & 0 & 4 & 34 \\
\hline
\end{tabular}

Cohen's kappa coefficient 0.6133

B

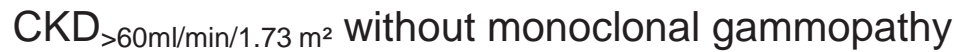

\begin{tabular}{|c|c|c|c|c|}
\cline { 3 - 5 } \multicolumn{2}{|c|}{$n=17$} & \multicolumn{3}{c|}{ Freelite FLC ratio } \\
\cline { 3 - 5 } \multicolumn{2}{c|}{} & $<0.26$ & $0.26-1.65$ & $>1.65$ \\
\cline { 3 - 5 } \multicolumn{2}{c|}{} & $\mathrm{n}$ & $\mathrm{n}$ & $\mathrm{n}$ \\
\hline \multirow{3}{*}{$\begin{array}{c}\text { N-Latex } \\
\text { FLC ratio }\end{array}$} & $0.31-1.56$ & 0 & 0 & 0 \\
\cline { 2 - 5 } & $>1.56$ & 0 & 14 & 0 \\
\hline
\end{tabular}

Cohen's kappa coefficient 0.7671

C

$\mathrm{CKD}_{\leq 60 \mathrm{ml} / \mathrm{min} / 1.73 \mathrm{~m}^{2}}$ with monoclonal gammopathy

\begin{tabular}{|c|c|c|c|c|}
\cline { 3 - 5 } \multicolumn{1}{c|}{} & \multicolumn{3}{c|}{ Freelite FLC ratio } \\
\cline { 3 - 5 } \multicolumn{2}{c|}{} & $<0.37$ & $0.37-3.1$ & $>3.1$ \\
\cline { 3 - 5 } \multicolumn{1}{c|}{} & $\mathrm{n}$ & $\mathrm{n}$ & $\mathrm{n}$ \\
\hline \multirow{2}{*}{$\begin{array}{c}\text { N-Latex } \\
\text { FLC ratio }\end{array}$} & $<0.31$ & 87 & 14 & 0 \\
\cline { 2 - 5 } & $0.31-1.56$ & 11 & 173 & 11 \\
\cline { 2 - 5 } & $>1.56$ & 0 & 30 & 181 \\
\hline
\end{tabular}

Cohen's kappa coefficient 0.7964

D

$\mathrm{CKD}_{\leq 60 \mathrm{~m} / \mathrm{min} / 1.73 \mathrm{~m}^{2}}$ without monoclonal gammopathy

\begin{tabular}{|c|c|c|c|c|}
\cline { 3 - 5 } \multicolumn{1}{c|}{} & \multicolumn{3}{c|}{ Freelite FLC ratio } \\
\cline { 3 - 5 } \multicolumn{2}{c|}{} & $<0.37$ & $0.37-3.1$ & $>3.1$ \\
\cline { 3 - 5 } \multicolumn{1}{c|}{} & $\mathrm{n}$ & $\mathrm{n}$ & $\mathrm{n}$ \\
\hline \multirow{2}{*}{$\begin{array}{c}\text { N-Latex } \\
\text { FLC ratio }\end{array}$} & $<0.31$ & 4 & 0 & 0 \\
\cline { 2 - 5 } & $0.31-1.56$ & 1 & 155 & 1 \\
\cline { 2 - 5 } & $>1.56$ & 0 & 4 & 2 \\
\hline
\end{tabular}

Cohen's kappa coefficient 0.9626 